\title{
Vascular Disrupting Agent BNC105P
}

National Cancer Institute

\section{Source}

National Cancer Institute. Vascular Disrupting Agent BNC105P. NCI Thesaurus. Code C88338.

\begin{abstract}
A benzofuran-based vascular disrupting agent (VDA) prodrug with potential anti-vascular and antineoplastic activities. Upon administration vascular disrupting agent BNC105P, the disodium phosphate ester of BNC105, is rapidly converted to BNC105; in activated endothelial cells, BNC105 binds to tubulin and inhibits its polymerization, which may result in a blockage of mitotic spindle formation, cell cycle arrest, and disruption of the tumor vasculature. Hypoxic conditions ensue, depriving tumor cells of nutrients and resulting in tumor cell apoptosis. In addition to its VDA activity, this agent has a direct cytotoxic effect on tumor cells by inhibiting tubulin polymerization. BNC105 is not a substrate for the multidrug-resistance P-glycoprotein (Pgp) transporter.
\end{abstract}

